\title{
Особенности психотического инсайта
}

\section{и его отражение в дневниках пациентов}

\author{
С.О. Бышок ${ }^{1}$, Г.Е. Рупчев ${ }^{1,2}$, Н.Д. Семёнова ${ }^{3}$ \\ ${ }^{1}$ ФГБоУ ВО «Московский государственный университет имени М.В. Ломоносова»; Россия, г. Москва \\ ${ }^{2}$ ФГБНУ «Научный центр психического здоровья»; Россия, г. Москва \\ ${ }^{3}$ ФГБУ «Московский научно-исследовательский институт психиатрии» Министерства здравоохранения Российской Федерации, \\ филиал ФГБУ «Национальный медицинский исследовательский центр психиатрии и наркологии имени В.П. Сербского» \\ Министерства здравоохранения Российской федерации; Россия, г. Москва
}

\section{РЕЗЮМЕ}

\begin{abstract}
Цель исследования: изучить формы проявления инсайта (осознания болезни) у больного параноидной формой шизофрении; показать динамику критичности в процессе личностно-социального восстановления и возможность ее актуализации (или реактуализации). Дизайн: описательное исследование, анализ единичного случая.

Материалы и методы. Изучены неструктурированные самоотчеты (дневники) пациента с параноидной формой шизофрении на трех временны́х отрезках: февраль 2000 г., октябрь - декабрь 2000 г. и ноябрь - декабрь 2002 г. Работа включала фиксацию фрагментов дневниковых записей, соответствовавших хотя бы одной характеристике инсайта, патопсихологический анализ фрагментов, выявление психопатологических объектов в фокусах инсайтов и анализ качественных изменений, происходивших с фокусами инсайтов.

Основные положения. Существует ряд отечественных и зарубежных подходов к пониманию инсайта при психических заболеваниях. Качественный анализ неструктурированных самоотчетов больного позволил сделать ряд важных предположений, одним из которых явилась гипотеза о существовании особой формы критичности, названной авторами психотической.

Заключение. Проблема инсайта при тяжелых психических заболеваниях, в частности при шизофрении, остается малоизученной и актуальной проблемой психиатрии и клинической психологии.

Ключевые слова: инсайт при психических заболеваниях, дневники больных шизофренией, метод анализа клинического случая, критичность у психически больных.
\end{abstract}

Вклад авторов: Бышок С.О. - сбор и обработка научного материала, проведение клинико-психологического анализа; Рупчев Г.Е. - разработка дизайна исследования и научное руководство; Семёнова Н.Д. - обзор новейших публикаций по теме статьи, утверждение рукописи для публикации.

Конфликт интересов: авторы заявляют об отсутствии возможных конфликтов интересов.

Для цитирования: Бышок С.О., Рупчев Г.Е., Семёнова Н.Д. Особенности психотического инсайта и его отражение в дневниках пациентов. Доктор.Ру. 2021; 67-73. DOI: 10.31550/1727-2378-2021-20-5-67-73

\section{Peculiarities of Psychotic Insight and Its Presentation in Patient's Diary}

\author{
S.0. Byshok ${ }^{1}$, G.E. Rupchev ${ }^{1,2}$, N.D. Semenova ${ }^{3}$ \\ ${ }^{1}$ Lomonosov Moscow State University; 11 Mokhovaya St., Bld. 9, Moscow, Russian Federation 125009 \\ 2 Scientific Centre of Mental Health; 34 Kashirskoe Shosse, Moscow, Russian Federation 115230 \\ ${ }^{3}$ V.P. Serbsky National Medical Research Center for Psychiatry and Narcology (a Federal Government-funded Institution), Russian Federation \\ Ministry of Health; 3 Poteshnaya St., Moscow, Russian Federation 107076
}

\section{ABSTRACT}

Study Objective: To study manifestations of insight (disease awareness) in paranoid schizophrenia patients; to demonstrate criticality dynamics during individual and social development and its possible actualisation (or re-actualisation).

Study Design: descriptive study, case study.

Materials and Methods. We have studied unstructured self-reports (diaries) of a patient with paranoid schizophrenia during three periods: February 2000, October - December 2000, and November - December 2002. Our work involved identification of diary entries which corresponded to at least one insight characteristic; psychopathological analysis of fragments; identification of psychopathological objects in insight focuses; and analysis of quality changes in insight focus.

Key Points. There are a number of Russian and foreign approaches to the notion of insight in mental disorders. A quality analysis of unstructured self-reports of the patient facilitated a number of important assumptions, including a hypothesis of a specific form of criticality, which we call psychotic.

Бышок Станислав Олегович - кафедра нейро- и патопсихологии факультета психологии ФГБоу ВО «МГУ им. М.В. Ломоносова». 125009, Россия, г. Москва, ул. Моховая, д. 11, cmp. 9. eLIBRARY.RU SPIN: 2820-5046. https://orcid.org/0000-0002-2441-4975. E-mail: sbyshok@gmail.com Рупчев Георгий Евгеньевич - к. п. н., старший научный сотрудник кафедры нейро- и патопсихологии факультета психологии ФГБОУ ВО «МГУ им. М.В. Ломоносова»; научный сотрудник лаборатории психофармакологии ФГБну НЦПЗ. 125009, Россия, 2. Москва, ул. Моховая, д. 11, cmp. 9. eLIBRARY.RU SPIN: 8523-1306. https://orcid.org/0000-0002-4440-095X.E-mail: rupchevgeorg@mail.ru

Семёнова Наталья Дмитриевна (автор для переписки) - к. п. н., ведущий научный сотрудник ФГБУ «Московский НИИ психиатрии» Минздрава России, филиала ФГБУ «НМИЦ ПН им. В.П. Сербского» Минздрава России. 107076, Россия, г. Москва, ул. Потешная, д. 3. еLIBRARY.RU SPIN: 2206-6374. https://orcid.org/0000-0001-7698-1018.E-mail: niyami2020@gmail.com 
Conclusion. The issue of insight in severe psychiatric disorders, especially in schizophrenia, has been studied poorly and is a burning aspect in psychiatry and clinical psychology.

Keywords: insight in psychiatric disorders, diaries by schizophrenia patients, clinical case analysis method, criticality in mentally ill individuals.

Contributions: Byshok, S.0. - collection and processing of scientific materials; clinical and psychological analysis; Rupchev, G.E. - study design and academic advising; Semenova, N.D. - review of latest thematic publications; approval of the manuscript for publication.

Conflict of interest: The authors declare that they do not have any conflict of interests.

For citation: Byshok S.0., Rupchev G.E., Semenova N.D. Peculiarities of Psychotic Insight and Its Presentation in Patient's Diary. Doctor.Ru. 2021; 20(5): 67-73. (in Russian). DOI: 10.31550/1727-2378-2021-20-5-67-73

\section{ВВЕДЕНИЕ}

Критичное отношение психически больных к своим психопатологическим переживаниям, мыслям, действиям, к своей личности в целом - важный фактор, влияющий на их позицию по отношению к лечебному процессу, на функционирование в социальной среде. При этом любой акт самоисследования, взгляд как бы со стороны на те или иные элементы внутреннего опыта, суть проявление критичного отношения, критичности [1]. Подразумевается наличие у субъекта минимальных ресурсов социального опыта, наличие представлений о «нормальности» и «ненормальности» тех или иных внутренних переживаний. Вслед за С.С. Корсаковым (1890) психиатры выделяют признаки, указывающие на выздоровление, среди них появление критичности и осознание болезни.

До недавнего времени в психиатрии отсутствовали четкие критерии и методики, с помощью которых можно было бы оценить степень критичности больных. Затем появились такие методики, созданные на основе структурированных самоотчетов и опросников [2]. Не умаляя важности подобного рода методик, следует указать на особую значимость оценки критичности и осознания болезни на основе неструктурированных самоотчетов пациентов, о чем писали еще классики психиатрии $[1,3]$.

\section{Клиническая эмпирия}

В рамках клинического подхода нарушение критичности больного, нарушение осознания болезни рассматривались через врачебный опыт непосредственного наблюдения за пациентом. Вводились описательные понятия, такие как «осознание болезни», «установки больного по отношению к собственной болезни» [4]. Клиницисты говорили и о рефлексии, благодаря которой больной может «видеть себя», «судить о себе», «формировать себя» [4].

К. Ясперс указывал на такой момент внутренней жизни пациента, как «решимость заболеть» - некая грань, отделяющая осознание себя здоровым от осознания себя больным. В каждом отдельном случае существует своя, индивидуальная грань, до которой человек осознает собственные переживания как нормальные, а после которой - как патологические; имеется определенный момент между здоровьем и болезнью, когда все зависит от самого человека [1].

\section{Подход теории деятельности к критичности}

В отечественной психологии личность исследовалась преимущественно через анализ ее деятельности. Некритичность рассматривалась как перестройка личностных особенностей, приводящая к невозможности вызвать установку на адекватное отношение к окружающей среде [5].

В условиях патопсихологического эксперимента нарушения критичности проявляются в неспособности испытуемого заметить ошибку, исправить ее даже при указании на это экспериментатора. Ситуация эксперимента может выявлять нару- шения критичности, а также способствовать ее актуализации, посредством чего можно формировать критичность [5].

И.И. Кожуховской выделены основные виды нарушений критичности в ходе патопсихологического исследования: к собственным суждениям, действиям и высказываниям; к собственной личности; к психопатологическим переживаниям [6].

Таким образом, в рамках отечественной психологии некритичность - это не столько нарушение мышления, сколько проявление расстройства личностной сферы больного.

\section{Психоаналитический подход к критичности}

В психоаналитических подходах критичность рассматривается, с одной стороны, как одна из функций Эго (способность к тестированию реальности, способность различать Я и не-Я, отличать внутрипсихическое, например фантазии, мысли, галлюцинации, от внешнего), с другой - как некий компромисс между защитными механизмами личности [7]. Без появления критичности к психопатологическим переживаниям нельзя говорить о ремиссии при шизофрении $[4,8]$.

Вместе с тем недостаток критичности при шизофрении в русле психоаналитических работ связывают с защитным механизмом отрицания и рассматривают как вполне понятную защиту человека от резкого снижения самооценки, неминуемого в случае осознания и принятия психического заболевания и необходимости лечения $[7,8]$.

\section{Понятие «инсайт» и современный эмпирический подход к критичности}

0 концептуальной и методологической недостаточности при изучении осознания болезни на психиатрических выборках писали еще X. Amador и соавт., призывая к переоценке данного явления и к введению единой терминологии [9]. Так был предложен термин «инсайт» (англ. insight), заимствованный из гештальтпсихологии, классического психоанализа, инсайт-ориентированной психотерапии $[9,10]$. При этом содержание термина изменилось: если в психотерапии под ним понимается моментальное озарение, момент осознания вытесненного, то в психиатрической практике личностная особенность, изначально присущая (или не присущая) пациенту.

Предлагались инструменты оценки инсайта [2, 11]. Изначально использовались размытые определения («вербальное признание пациентом существующих психологических сложностей» и т. п.), пациенты опрашивались на предмет их отношения к болезни и далее разделялись на группы (с полным инсайтом, частичным инсайтом, не имеющие инсайта). Затем внимание стали уделять именно самоотчетам пациентов и инсайт начал представляться как некий континуум. Обращение к продукции пациента, спонтанно появляющейся в ходе лечения, субъективные критерии выздоровления вкупе с исследованиями качества жизни и проявлений «нейрокогнитивного дефицита» - все это получило 
широкое распространение в психиатрии [8]. В настоящее время инсайт не укладывается в бинарную систему («есть» или «нет»), а представляет собой континуальное понятие, где осознание болезни - лишь один из его аспектов [11].

Современное понимание инсайта включает осознание пациентом собственного душевного расстройства, социальных последствий этого расстройства и необходимости лечения, осознание своих необычных переживаний (симптомов) как патологических, способность приписывать симптомы болезни. Различают несколько степеней инсайта [12]: 1) полное отрицание болезни; 2) неполное осознание болезни (больной обращается к врачу за помощью, но вместе с тем отрицает, что он болен); 3) больной осознает, что болен, но обвиняет в болезни окружающих или связывает болезнь с внешними обстоятельствами (в том числе с органическим поражением мозга); 4) больной объясняет болезнь чем-то таинственным, мистическим, непознаваемым; 5) адекватная самооценка, или «интеллектуальный инсайт», как признание факта болезни при неспособности применить критическую самооценку в будущем в качестве средства против патологических проявлений; 6) истинно адекватная самооценка, или «истинно эмоциональный инсайт», как осознание и адекватная эмоциональная реакция больного на свои мотивы и ощущения, адекватные отношения со значимыми другими. Клиницистам рекомендуют вносить в историю болезни степень инсайта и далее прослеживать его динамику в процессе лечения [12].

Пациенты с психотическими расстройствами обнаруживают низкие показатели инсайта $[11,12]$. Низкий инсайт связан с малой эффективностью лечения [12], с риском развития суицидальных идеаций, особенно при первом эпизоде болезни [10], а хорошие показатели инсайта с личностно-социальным восстановлением и лучшей трудовой адаптацией [12].

Инсайт в его связи с комплаенсом достаточно давно привлекает внимание исследователей [13-15]. Среди причин несоблюдения лечебных рекомендаций выделяют факторы, связанные с самим пациентом, прежде всего бедный инсайт, а также факторы коморбидности с нарушениями по типу злоупотребления веществами $[16,17]$. Некомплаентность ведет к неудачам лечения, повышению морбидности и росту числа рецидивов, тогда как более полный инсайт способствует личностно-социальному восстановлению.

\section{Клинико-психологический анализ единичного случая и проблема инсайта}

Еще Фрейд заложил основы индивидуально-психологического подхода к психопатологии (случаи Анны 0., Доры, Маленького Ганса, Шребера и др.). Далее стала развиваться методология клинико-психологического анализа единичного случая, позволяющего исследователю строить теоретическую модель и разрабатывать концепцию оказания помощи. Человек может представлять собой пример ситуации, некую фактологическую основу (так, врач может говорить о случае заболевания шизофренией, о случае, хорошо или плохо поддающемся лечению), или выступать как «неповторимая» личность, не входящая в «выборку».

Индивидуально-психологическое рассмотрение дает возможность «увидеть» инсайт таким, каким он проявляется в реальной жизни, у данного конкретного пациента. Внимание при этом уделяется не столько идентификации нозологической принадлежности случая, сколько конкретной, индивидуально обусловленной феноменологии.
Клиницист старается понять сокрытое, «закодированное» послание, находящееся в неструктурированных самоотчетах (например, в тексте дневников пациента). Важно знать способ «кодировки» послания, формы осознания болезни и проявления разума в болезни - почему происходит осознание и как оно происходит. Добавим, что некоторая парадоксальность ситуации заключается в том, что послание может быть «закодировано» не только для клинициста, но и для самого пациента.

Цель исследования: изучить, в каких формах проявляется осознание болезни (инсайт) у больного параноидной формой шизофрении; показать динамику критичности в процессе личностно-социального восстановления и возможность ее актуализации (или реактуализации).

Задачи исследования: 1) изучить дневниковые записи пациента и определить фрагменты для исследования; 2) провести патопсихологический анализ данных фрагментов.

\section{МАТЕРИАЛЫ И МЕТОДЫ}

Работа выполнена в рамках методологии анализа единичного случая. Материалами исследования служили дневники и история болезни пациента Б. (1975 года рождения). Возраст пациента на момент исследования - 25 лет.

История болезни: манифест заболевания произошел осенью 1995 г. (в возрасте 20 лет). В октябре 1996 г. пациент поступил на лечение в стационар психиатрической клиники, где пробыл до февраля 1997 г. Первичный диагноз: шизофрения шубообразная, аффективно-бредовой приступ. В июле 1998 г. вторично помещен в клинику, где пробыл месяц. Диагноз: шизофрения параноидная, непрерывно-прогредиентное течение, с выраженными изменениями личности в эмоционально-волевой сфере и социально-трудовой дезадаптацией, галлюцинаторно-параноидный синдром.

В период написания дневников Б. принимал антипсихотические препараты, лечился амбулаторно.

Работа с материалами дневников и соотнесение их с данными истории болезни осуществлялись в следующем порядке: фиксировались фрагменты дневниковых записей, соответствовавшие хотя бы одной из характеристик инсайта; проводился патопсихологический анализ фрагментов; выявлялись психопатологические объекты, попадавшие в фокус инсайта; анализировались качественные изменения, которые происходили с фокусами инсайтов. Динамика прослеживалась по трем временны́м отрезкам: февраль 2000 г., октябрь - декабрь 2000 г. и ноябрь - декабрь 2002 г.

\section{РЕЗУЛЬТАТЫ И ОБСУЖДЕНИЕ}

Со слов пациента, первоначальной целью ведения дневника было зафиксировать то, что он впоследствии скажет лечащему врачу. Спустя время дневник стал средством общения пациента с самим собой, средством психологической саморегуляции.

\section{(февраль 2000 г.)}

\section{Психопатологические объекты, на которые направлен инсайт}

\section{Психические автоматизмы и деперсонализация.}

Б. пишет об ощущении внутри себя другого человека, который «тянет» его совершить неадекватные поступки, могущие привести к негативным последствиям для него самого (например, броситься с моста в Москву-реку) и окружающих. Интеллектуальный инсайт: «У меня такое впечатление, что кто-то хочет покончить мою жизнь самоубийством. И все же я отчетливо понимаю, что этого не может быть». 
В другом месте Б. пишет о «явственном ощущении внушенности» мыслей.

Борьба с навязчивыми тенденциями сопровождается страхом, которого больной не может объяснить. Возможно, имеет место витальный страх за жизнь и существование, который мало рефлексируется, но в известной мере препятствует совершению опасных для больного и окружающих поступков. Критичность проявляется в виде интеллектуального понимания и в косвенной форме: Б. указывает на «впечатление» воздействия извне, а не на реальное воздействие.

Дереализация. Б. пишет о «впечатлении», что «вместо глаз, головы и тела» у него «монитор, транслирующий окружающий мир», - здесь также употреблено слово «впечатление». 0н упоминает о трудностях в плане адекватного восприятия «предметов», которые от него «на расстоянии», видя причину этого в том, что «мозг не перерабатывает информацию», - симптом нарушения восприятия приписывается болезни.

Сенестопатии. Б. часто упоминает о неприятных и тягостных ощущениях непонятного происхождения в разных частях тела («ломание» и «нервный зуд... внутри ног и рук»), с которыми пытается справиться с помощью причудливых телодвижений (вис вниз головой и пр.). Далее он начинает считать эти ощущения «ненормальными», то есть они становятся новыми объектами в фокусе инсайта. Сенестопатии Б. объясняет тем, что в то время «на самом деле... болела нервная система».

Навязчивые мысли. Б. пишет об «одолевающих навязчивых идеях», связанных с деперсонализацией и психическими автоматизмами (как в случае с желанием прыгнуть с моста в Москву-реку). «Раз в голове есть голоса, которые заставляют меня [сделать нечто опасное], я должен мысленно сопротивляться и подавлять их».

Слуховые галлюцинации. «Раньше голоса были сами по себе, а я сам по себе. Я не мог отличить голоса от собственных мыслей», - пишет Б. Теперь же, по его словам, «бывает так, что в голове возникает какой-то расплывчатый образ», который он начинает «развивать». Это изменение можно интерпретировать как частичное преодоление пациентом расщепления и «раздвоенности» психики.

«Голоса говорили мне... А может, это были не голоса, а мои мысли, которые очень напоминали голоса», «Голоса называют меня трусливым, плохим. Таким оценивают меня голоca, да и я сам себя так же оцениваю» - в самом построении этих фраз заметна путаница с определением своей позиции и позиции «голосов». Самооценка Б. здесь совпадает с критической оценкой его «голосами». Далее упоминаются «полуголоса, полумысли», возникающие вместе с сенестопатиями, очевидна неопределенность данных феноменов для больного, он не знает, отнести ли их к (своим) мыслям или к (внешним) «голосам». Б. вспоминает о «странных мыслях», посещавших его во время службы в армии: «Они появлялись как наваждение, подавляли разум и создавали извращенное понимание моего места в обществе, извращали оценку происходящих событий... Эти сумасшедшие мысли звучали как "голоса"».

Выздоровление Б. связывает с избавлением от слуховых галлюцинаций: «Полностью спокойным я смогу быть только в том случае, если в голове не будет голосов».

Интерпретативный бред. Б. пишет о поисках «знаков», якобы установленных для него «колдунами и спецслужбами». «Знаки» должны были привести Б. к знакомой девушке. В оценке событий прошлого он ориентируется на «здравое» понимание жизненных ситуаций, противопоставляя его пониманию ложному, исходящему из болезни: «Если рассуждать здраво, то мне нужно было всего лишь узнать ее телефон через приятеля». Тогда же Б. «помимо воли, вопреки желанию концентрировал внимание на "условных сигналах"».

Страхи. Б. боится, что «в какой-то момент утратит контроль над собой и сделает что-нибудь с окружающими или с собой». Он пишет о навязчивых страхах и об ощущении всемогущества, связанного с возможностью «взглядом останавливать страх». «Голоса» же говорят: «Так каждый может. А ты попробуй словами мысленно победить страх». Инсайт: "Страх основан на непонимании природы видений [будущего]. Нормальное предвидение предстоящих действий я объяснял внушенными колдунами мыслями. Или вообще - психотропным оружием».

Ложное узнавание. Пациент видит в иконе, изображающей Христа, поочередно некоторых родственников и знакомых и задается вопросом: «Нормально ли это?»

Специфические формы критичности (психотический инсайт). «Голоса требуют, чтобы мысли шли, что называется, "от души". Это важное воспоминание». Сами «голоса» «требуют», чтобы мысли Б. шли «от души», то есть чтобы мысли были именно его мыслями, а не навязанными ему извне. Критичность объективируется, проявляясь в форме «голосов»: «Голоса обвиняют меня в том, что в моей голове существуют голоса». Инсайт «встраивается» в галлюцинацию (псевдогаллюцинацию). Б. пишет о существовавшей у него идее «не иметь своего мнения» и о «стремлении поступать так и делать то, что ожидали окружающие» возможно, так проявляется идея конвенциональности, встроенная, однако, в бредовую систему «эксперимента».

Отношение к своей личности, окружающему миру и болезни. Б. строит гипотезы по поводу причин заболевания и видит «одну из причин сумасшествия» в «раздвоенности и противоречивости души». Он отмечает, что «должен быть хорошим человеком, имеющим твердые убеждения и четкую жизненную позицию», и подчеркивает, что «все это нужно, чтобы не сойти с ума». Б. пишет, что «вел двуличную жизнь», выражавшуюся, с одной стороны, в «стремлении расположить к себе окружающих», а с другой в скрытом (паранойяльном) противостоянии им.

«Если оценивать мой духовный мир, то он менялся на протяжении последних лет. В последнее время мое мировоззрение становится таким же, каким было [до начала болезни]... то есть приходит в норму». Б. атрибутирует психопатологические переживания (в частности, идеи о наведенной порче и сглазе) болезни: «Мне неприятно вспоминать это, но, думаю, в этой моей слабости виновен не я, а болезнь». И далее: «Если с кем-то что-то случается, то это не вина (или, наоборот, заслуга) какого-нибудь колдуна, а просто так случилось». Идеи относительно будущего: «Строить планы на будущее, конечно, надо. Только они должны быть выполнимыми. Нельзя мечтать о несбыточном и маловероятном. Бредовые фантазии искажают правильное понимание действительности».

\section{(октябрь - декабрь 2000 г.)}

Зрительные галлюцинации. «Я вижу то, чего нет на самом деле. Я не знаю, как это назвать. Галлюцинации, наверное». Б. осознает свои симптомы как психопатологические, называя их галлюцинациями, он способен тестировать реальность.

Слуховые галлюцинации. «Я думаю (или слушаю голоса) о какой-нибудь своей проблеме». Болезненное расщепление частично преодолевается. Пациент Б. вспоминает, 
что в прошлом «не знал, что голоса - это психическое заболевание, слышать голоса - не нормально».

Галлюцинаторно-параноидный синдром. Рассуждая o «перенесенном психическом заболевании», Б. описывает феномены, относимые к синдрому Кандинского - Клерамбо (бред преследования со слуховыми галлюцинациями). Больной характеризует переживания прошлого как «навязчивые идеи», «внутреннюю убежденность» и «полный бред». Он пишет: «Следят за многими людьми... Но постепенно подозрительность стала навязчивой».

Появилась критичность к бреду преследования, симптом стал Эго-дистонным. Б. приписывает свои психопатологические переживания болезни: «Самое ужасное в моем заболевании было то, что я считал все происходящее во мне и вокруг меня не болезнью, а управляемым экспериментом (хотя иногда соглашался мысленно с тем, что я все-таки болен)».

Специфические формы критичности (психотический инсайт). Б. пишет, что во время болезни считал борьбу с «голосами» «испытанием», которое он должен пройти, чтобы доказать (кому?), что он «настоящий человек». Б. не решался рассказать о «голосах» даже врачам, так как они были включены в его бредовую систему. Позже у Б. появилась идея, что он «не должен верить звучащим мыслям», а должен «не слушаться и бороться с голосами». Сама мысль о ненормальности «голосов» и необходимости «бороться» с ними суть проявление инсайта.

Отдельного рассмотрения заслуживает соотношение между инсайтом, представлениями о «нормальности» и архаичным супер-Эго больного (необходимостью доказать, что он «настоящий человек»). Проявление разума в болезни: «Даже когда я себя плохо чувствовал, в голове появлялись правильные мысли».

Отношение к своей личности, окружающему миру и болезни. «Я чувствую, что постепенно выздоравливаю. Впереди у меня жизнь. Надеюсь и хочу верить, что жизнь будет долгой. Какой она будет, я не знаю». Б. признает неопределенность будущего, невозможность точно «nростроить» будущее, свои действия и поступки, как того требуют «голоса» и архаичное супер-Эго.

Он начинает воспринимать себя более реалистично: «Я должен понимать - я не суперчеловек и не избранник Богов. Мысли о себе как о мессии недопустимы». Принимает неоднозначность, амбивалентность происходящего в жизни: «Может, это примитивно, зато понятно. А жизнь - сложна, в ней много непонятного. Неоднозначного - еще больше. Почти все в жизни имеет положительные и отрицательные стороны». Б. не обесценивает настоящее, старается найти в нем положительное: «Когда окончательно выздоровлю и буду снова умным, сильным, целеустремленным, я не должен отказываться от того хорошего, что имею в душе сейчас». Он пишет о необходимости «критичного отношения к себе и своим родственникам» и о том, что не стоит сразу отворачиваться от человека, совершившего «некрасивый поступок», нужно сначала «попытаться понять».

Б. так отзывается о своем нынешнем состоянии (ремиссии): «Находиться в теперешнем состоянии, так думать и так чувствовать - это просто нормально». Он имеет представление о «норме» и «нормальности» и может сравнивать нынешнее состояние с состоянием в период обострения.

(ноябрь - декабрь 2002 г.)

Постшизофреническая депрессия. «Кто я? Никто! У меня ничего нет и вряд ли что-нибудь когда-нибудь появит- ся. Даже работы нормальной нет. Я просто больной человек». «Мало того что больной - я еще и необразованный, тупой, недалекий». «Я никогда не стану праведником». «Просто я шизофреник. И вообще, если без шуток - я несчастный человек». «Я болен шизофренией, то есть я дурак. Мне очень не нравится чувствовать себя дураком». Фокус внимания смещается с отношений «Я - симптом» на отношения «Я окружающий мир» и «Я - последствия болезни».

Б. вспоминает о попытке самоубийства в период обострения болезни, за несколько лет до настоящего момента. Подробно описывая этот эпизод (порядка 420 слов), он называет «дурацкими бреднями», «навязчивыми идеями» и «шизофренией» представление о том, что, сделав себе «не смертельное» ранение в грудь, сможет избавиться от тягостных симптомов. В записях ноября - декабря 2002 г. Б. неоднократно возвращается к теме суицида, признавая значимость проработки, «проговаривания» темы: «Я сделал неожиданный вывод - чем больше говорю о самоубийстве, тем меньще вероятность того, что покончу с собой».

Слуховые галлюцинации. «Место голосов заняли мысленные диалоги с собой». Б. приходит к выводу, что тот, кто «отвечает» ему, - это он сам: «Я говорю что-то, а потом представляю возможный ответ. Это уже после мне кажется, что кто-то мне отвечает, беседует со мной». Описывая ситуацию, когда «голоса» призывали стать «хорошим человеком» и пр., Б. прерывает себя: «Что за бред! Понятное дело я сам стремился стать хорошим человеком». Вместо объекта интенции мысли Б. становится ее субъектом, вновь обретая контроль над мыслями, стремлениями, представлениями.

Из человека, страдающего от слуховых галлюцинаций, Б. превращается в «носителя голосов»: «Теперь я просто не обращаю внимания на голоса. Они не мешают или их вообще нет». Постепенно «голоса» теряют связь с психопатологией, становясь одной из специфических форм мышления: «Меня не беспокоит раздвоенность, не беспокоят голоса, не беспокоят непонятные боли. Все это сохраняется, но я привык жить с этим и это мне не мешает». Совладать с периодически возникающим наплывом мыслей теперь проще, так как увеличилась степень подконтрольности мышления воле (в психоаналитической трактовке - усилилось Эго): «Обычно помогает избавиться от навязчивых мыслей, если удается отвлечься, переключиться или несколько раз мысленно пропеть хорошую песню».

Однако у Б. остается некоторая резидуальная симптоматика: «Когда слышу голоса или чувствую проявление болезни, с одной стороны, мне понятно, что это болезнь, с другой стороны, кажется, что продолжается эксперимент с психотропным оружием, спецслужбами, колдунами и прочей ерундой». Феномен «двойной ориентации» - один из признаков возвращения к нормальному, вероятностному мышлению.

Отношение к своей личности, окружающему миру и болезни. «Я уверен, что выздоровел. К сожалению, это ощущение здравого ума и полного контроля над собой пройдет. Я снова начну испытывать стрессы, пойду на работу, мне будет казаться, что люди думают и говорят обо мне. На работе буду чувствовать себя неуверенно, а дома опять буду скандалить с мамой. Это будет потом. А сейчас мне просто очень хорошо». Звучит тема будущего. Б. признает неопределенность и возможную опасность событий, которые могут случиться впоследствии, он становится более устойчивым к стрессам, а его мышление - более ориентированным на реальность (усиление Эго): «Я не знаю, что будет. Удастся ли найти хорошую работу или придется 
отказаться от работы из-за болезни? Не знаю, буду ли чувствовать себя лучше или хотя бы так же, как сейчас. Хотя даже сейчас я чувствую себя так хорошо, что считал бы себя вообще здоровым, если бы не отдельные симптомы, возвращающие к печальной реальности». Он пишет: «Я все равно буду планировать жизнь и давать себе установки. Но я не могу планировать судьбу, не могу знать, сбудется то, что я наметил, или нет».

Б. рассматривает возможные варианты развития жизни, если бы не случилось болезни, пытается понять не только свои страдания, но и страдания родителей. Лишь недавно Б. стал понимать, как им «тяжело жить». Он смог объективировать свой болезненный опыт и перенести его на значимых других (родителей).

Признавая ограниченность своих возможностей (по сравнению с периодом до болезни), Б. обеспокоен «отсутствием страха перед плохим развитием дальнейшей жизни». «Меня почти не волнует болезнь и ее симптомы. Мне интересно получить ответы на вопросы: кто я? какой я?» - Б. пишет о себе как о целостной, включенной в социум личности. Борьба с одолевающими симптомами сменилась поиском себя в мире социальных отношений. Фокус самоисследования сместился с отношений «Я - болезнь» к отношениям «Я - окружающий мир»: «Мне становится легче жить, когда записываю то, что волнует. Если раньше волновала шизофрения и симптомы, то теперь волнует то, какой я есть и каковы мои отношения с людьми. Раньше о болезни я писал, чтобы не забыть, что рассказывать врачам, - я писал для врачей. Теперь пишу для себя».

Рассуждая о причинах болезни, Б. отмечает, что «наверное, только врачи ответят на этот вопрос». Хотя и врачи теперь перестают быть всесильными, все понимающими, коими воспринимались прежде: «Даже врачи до конца не понимают, как мне было плохо».

Далее при обсуждении результатов представлены даты и соответствующий им характер осознания психопатологических переживаний.

\section{Патопсихологический анализ динамики инсайта} (февраль 2000 г.)

На первом плане - описание случаев и фактов деперсонализации и дереализации, а также психических автоматизмов с полной или, чаще, частичной критичностью. Б. также пишет о сенестопатиях и попытках справиться с ними. Хотя больной находится в состоянии поглощенности психопатологическими переживаниями, он строит гипотезы о причинах заболевания и видит их в «раздвоенности и противоречивости» своей личности. «Раздвоению души» Б. приписывает также неудачи в социальной жизни.

Отметим специфическую форму проявления критичности (психотический инсайт): критическое отношение к психопатологическим переживаниям выражается с помощью психопатологических же средств (как правило, слуховых галлюцинаций императивного характера).

Описываемые феномены относятся к настоящему времени, однако имеются и ретроспективные включения. Ориентация на будущее связана с желанием избавиться от «голосов».

(октябрь - декабрь 2000 г.)

На первый план выступает своеобразная «полемика» Б. с жестким психотическим супер-Эго, императивы которого («делай то-то» и пр.) формально сходны с повелевающими «голосами». Отметим подчеркивание или взятие в рамочку таких императивов в тексте, что указывает на их особую важность для Б. Больной составляет «план действий», следуя которому сможет жить нормально. Критика связывается с попытками «смягчить» суровые императивы, с более мягкой их интерпретацией.

Обращает на себя внимание Эго-синтонность императивов: они являются выражением неоднократно встречающейся в записях идеи «быть хорошим человеком». У Б. всегда наличествует некая оглядка на «кодекс честного поведения», что помогает ему выйти на конвенциональный уровень функционирования, несмотря на захваченность психопатологическими переживаниями. Этот «кодекс», хоть и принимает ригидные и архаические формы, служит важным подспорьем, поддерживающим Б. и не дающим ему «провалиться» в психоз.

Отмечаются страхи (потери контроля, рецидива болезни), признается необходимость «следить за собой». Появляется большое количество записей, связанных не непосредственно с борьбой с наличествующими психопатологическими переживаниями, а с осознанием себя в мире социальных отношений и ситуаций (темы: работа, близкие люди, отношения с женщинами и пр.).

Прослеживается «путаница» собственных мыслей Б. и «голосов». Если раньше Б. различал мысли и «голоса», то теперь затрудняется это сделать. Это может рассматриваться как признак частичного преодоления шизофренического расщепления, постепенной интеграции «отщепленных» мыслей и чувств.

Описываемые феномены относятся к настоящему и прошлому. Доминируют ретроспективные описания, что позволяет предположить отсутствие ярко выраженной симптоматики при написании этой части дневников. Часто появляются рассуждения о будущем - заметно признание его неопределенности, даже при следовании «кодексу хорошего человека».

\section{(ноябрь - декабрь 2002 г.)}

На первый план выступают отчетливые признаки постшизофренической депрессии: суицидальные мысли, самообвинение, ощущение собственной социальной несостоятельности.

Основной темой нарратива являются не воспоминания и описание собственных психопатологических переживаний, как это было ранее, а попытки осознать себя и свое место в обществе, осмыслить или переосмыслить отношение к прошлому и, главное, к настоящему. Б. рассматривает свои жизненные перспективы, учитывая факт ограниченности, связанный с болезнью и ее последствиями. Отметим страхи возможного рецидива заболевания.

Обращает на себя внимание ориентация Б. на конвенциальность, проявляющаяся в способах реагирования на окружающее, отношении к себе. Высмеивание самого себя, шутки, связанные с болезнью, также могут рассматриваться как проявление конвенциональной реакции на неконвенциональные (психопатологические) переживания; Б. способен объективировать психопатологические переживания, обозначить их. Сверхконкретность мышления, обусловленная шизофренией, преодолевается, появляется возможность символизации опыта.

В тексте резко уменьшается количество жестких императивов. Четкая датировка, появившаяся в дневниковых записях этого периода, может быть интерпретирована как возвращение Б. на конвенциональный уровень функционирования. Продолжается процесс «интеграции» собственных мыслей и «голосов», в известной мере преодолевается шизофреническое расщепление. 
Описываемые психопатологические феномены относятся в основном к прошлому. Производя ретроспективный критический анализ психопатологических переживаний, Б. составляет своего рода субъективную этиологию болезни. При этом даже в ретроспективных описаниях отчетливо проявляется ориентация на будущее.

$$
* * *
$$

Нами прослежена динамика инсайта: от фрагментарного (в начальных записях) до практически полного. Далее все психопатологические переживания пациент атрибутирует болезни или ее последствиям. В записях происходит постепенный переход от концентрации на борьбе с психопатологическими переживаниями к осознанию (как процессу) своей личности, включенной в мир социальных отношений. Отмечается постепенная интеграция «голосов» и собственных мыслей: если сначала пациент был сконцентрирован на борьбе с «голосами», на «спорах» с ними, то впоследствии он более концентрируется на планах на будущее, на внешнем мире, а звучащие мысли принимает и воспринимает как факт. Жизнь Б. постепенно возвращается в «нормальное» русло, хотя пережитый психоз оставил серьезный отпечаток на его личности.

\section{Выводы}

Душевные переживания не могут предстать перед глазами исследователя с очевидностью физического объекта при их реконструкции следует опираться на документальные свидетельства в виде неструктурированных самоотчетов (дневников пациентов).

Инсайт может быть осмыслен как динамическое образование, в фокус которого в разные периоды болезни попадают различные психопатологические объекты. Исследование дневников пациента Б., относящихся к трем временны́м интервалам, выявило некоторые закономерности смещения фокуса. На ранних стадиях болезни и в период обострения в фокус инсайта попадают отдельные психотические симпто-

\section{ЛИТЕРАTУPA / REFERENCES}

1. Ясперс К. Общая психопатология. М.: Практика; 1997. 1056 с. [Jaspers K. General Psychopathology. M.: Praktika; 1997. 1056 p. (in Russian)]

2. Marková I.S., Berrios G.E. The assessment of insight in clinical psychiatry: a new scale. Acta Psychiatr. Scand. 1992; 86(2): 159-64. D0I: 10.1111/ j.1600-0447.1992.tb03245.x

3. Bleuler E. Руководство по психиатрии. М.: изд-во Независимой психиатрической ассоциации; 1993. 524 c. [Bleuler E. Psychiatric Guide. M.: Izdatel'stvo Nezavisimoj psihiatricheskoj associacii; 1993. 524 p. (in Russian)]

4. Снежневский А.В. Общая психопатология: Курс лекций. М.: МЕДпресс-информ; 2001. 208 c. [Snezhnevskij A. General Psychopathology: Course of Lectures. M.: MEDpress-inform; 2001. 208 p. (in Russian)]

5. Зейгарник Б.В. Патопсихология. М.: изд-во МГУ; 1986. 288 с. [Zejgarnik B. Pathopsychology. M.: Izdatel'stvo Moskovskogo universiteta; 1986. 288 p. (in Russian)]

6. Кожуховская И.И. Нарушение критичности у психически больных. М.: изд-во МГУ; 1985. 86 с. [Kozhuhovskaya I. Disturbances of criticality in the mentally ill. M.: Izdatel'stvo Moskovskogo universiteta; 1985. 86 p. (in Russian)]

7. Томэ Х., Кэхеле Х. Современный психоанализ: Исследования. СПб.: изд-во ВЕИП; 2001. 304 с. [Thomä H., Kächele H. Contemporary Psychoanalysis: Research. SPb.: Izdatel'stvo VEIP; 2001. 304 p. (in Russian)]

8. Lopez-Morinigo J.-D., Ajnakina 0., Martínez A.S.-E., Escobedo-Aedo P.-J., Ruiz-Ruano V.G., Sánchez-Alonso S. et al. Can metacognitive interventions improve insight in schizophrenia spectrum disorders? A systematic review мы, тогда как на стадии ремиссии фокус смещается - инсайт направляется на осознание места в социуме, построение «нормальных» отношений с окружающими, планирование будущего с учетом последствий перенесенного психоза, а упоминания отдельных симптомов (резидуального характера) становятся редкими.

При анализе дневников пациента Б. обнаружена форма проявления критичности (инсайта), которую нельзя отнести ни к одной из принятых в психиатрической классификации форм (полная, формальная или отсутствие критичности). Эту форму критичности можно назвать психотическим инсайтом: критичность «встраивается» в психопатологические симптомы. При этом, формально являясь психопатологическими (то есть относящимися к болезни), некоторые объекты сознания могут иметь позитивный, «здоровый» смысл. В частности, проявлениями психотического инсайта являются «голоса», предостерегающие больного от совершения недопустимых действий или сообщающие о том, что нынешнее состояние является ненормальным, болезненным.

\section{ЗАКЛЮЧЕНИЕ}

Оценивая проявления критичности (инсайта), клиницистам следует обращать внимание не только на явные формы (выражающиеся, в частности, в атрибуции психопатологических переживаний), но и на неявные, скрытые формы, к которым относится психотический инсайт. В целях дальнейших исследований психотический инсайт как явление требует операционализации.

Для получения более полной информации об успешности лечения представляется важным оценивать проявления инсайта в развитии. Важно определить, какие формы критичности выступают на первый план в те или иные периоды времени, с чем может быть связано изменение фокуса инсайта.

Неструктурированные самоотчеты (дневники) больных, наряду с опросниками и иными методиками, могут стать важным подспорьем для клиницистов в попытке понять пациента и назначить наиболее подходящее лечение.

and meta-analysis. Psychol. Med. 2020; 50(14): 2289-301. DOI: 10.1017/S0033291720003384

9. Amador X., David A. Insight and Psychosis. New York: Oxford University Press; 1998. $402 p$.

10. Jacob K.S. Insight in psychosis: A critical review of the contemporary confusion. Asian J. Psychiatr. 2020; 48: 101921. DOI: 10.1016/j. ajp.2019.101921

11. Elowe J., Conus P. Much ado about everything: A literature review of insight in first episode psychosis and schizophrenia. Eur. Psychiatry. 2017; 39: 73-9. DOI: 10.1016/j.eurpsy.2016.07.007

12. Vohs J.L., George S., Leonhardt B.L., Lysaker P.H. An integrative model of the impairments in insight in schizophrenia: emerging research on causal factors and treatments. Expert Rev. Neurother. 2016; 16(10): 1193-204. DOI: 10.1080/14737175.2016.1199275

13. Van Camp L.S.C., Sabbe B.G.C., Oldenburg J.F.E. Cognitive insight: A systematic review. Clin. Psychol. Rev. 2017; 55: 12-24. D0I: 10.1016/j. cpr.2017.04.011

14. Rao K.N., George J., Sudarshan C.Y., Begum S. Treatment compliance and noncompliance in psychoses. Indian J. Psychiatry. 2017; 59(1): 69-76. DOI: 10.4103/psychiatry.IndianJPsychiatry_24_17

15. Kalucha S., Mishra K.K., Gedam S.R. Noncompliance in psychosis. J. Datta Meghe Inst. Med. Sci. Univ. 2017; 12(1): 61-5.

16. Lysaker P.H., Vohs J., Hillis J.D., Kukla M., Popolo R., Salvatore G. et al. Poor insight into schizophrenia: contributing factors, consequences and emerging treatment approaches. Expert Rev. Neurother. 2013; 13(7): 785-93. DOI: 10.1586/14737175.2013.811150

17. Xavier R.M., Vorderstrasse A. Neurobiological Basis of Insight in Schizophrenia: A Systematic Review. Nurs. Res. 2016; 65(3): 224-37. DOI: $10.1097 /$ NNR.0000000000000159 D 